Energy Research Journal 1 (2): 193-196, 2010

ISSN 1949-0151

C 2010 Science Publications

\title{
Modeling and Optimization of the Vortex Tube with Computational Fluid Dynamic Analysis
}

\author{
K.K. Zin, A. Hansske and F. Ziegler \\ Department of Energy Conversion Engineering, \\ Technical University of Berlin, Sekr. KT 2, \\ Marchstraße 18, 10587 Berlin, Germany
}

\begin{abstract}
Problem statement: This study illustrated the influence of the Length to Diameter (L/D) on the fluid flow characteristics inside the counter-flow Ranque-Hilsch vortex tube predicted by Computational Fluid Dynamic (CFD) and validated through experiment. Approach: The swirl velocity, axial velocity, radial velocity component and also secondary circulation flow (back-flow) along with the pressure within the vortex tube were simulated and proved. Results: The standard kepsilon turbulence model which is one of the standard turbulence models of FLUENT ${ }^{\mathrm{TM}}$ was being used. As a first step, results of simulation will be presented also with varying amounts of cold faction. Conclusion/Recommendations: In the present study, the velocity and the pressure were investigated along the axial and radial directions to understand the flow behavior inside the tube.
\end{abstract}

Key words: Ranque-Hilsch vortex tube, CFD simulation, design parameters, k-epsilon model

\section{INTRODUCTION}

The Ranque-Hilsch vortex tube having, relatively simple geometry, no moving mechanical parts, was invented by Ranque (Hansske et al., 2007) (Fig. 1). Many investigators have suggested various theories to explain the Ranque effect. Most important seems to be a study by Ahlborn et al. (1998) in which a theory of temperature separation based on a heat pump mechanism which is enabled by a secondary circulation flow is proposed. However, till today no exact description has emerged to explain the phenomenon satisfactorily. Thus much of the design and development of vortex tubes has been based on empirical correlations only leaving much room for optimization of critical parameters. Vortex flows or swirl flows have been of considerable interest over the past decades because of their occurrence in industrial applications, such as furnaces, gas-turbine combustors and dust collectors (Fig. 2). The vortex tube has been used in industrial applications of cooling and heating processes because of being a simple, compact, light and quiet (in operation) device (Bruno, 1992).

\section{MATERIALS AND METHODS}

Numerical modeling: A numerical model of the Ranque-Hilsch vortex tube has been created by using the
FLUENT $^{\mathrm{TM}}$ software package. The model is threedimensional, steady state, source-free and employs the standard k-epsilon turbulence model. The RNG k-epsilon turbulence model and more advanced turbulence models such as the Reynolds stress equations were also investigated, but these models could not be made to converge for this simulation yet.

The equation for conservation of mass and momentum are as follow:

$$
\frac{\partial \mathrm{P}}{\partial \mathrm{t}}+\nabla \cdot(\rho \vec{v})=0
$$

$\frac{\partial \mathrm{p}}{\partial \mathrm{t}}(\rho \vec{v})+\nabla \cdot(\rho \vec{v} \vec{v})=-\nabla \mathrm{p}+\nabla \cdot(\mathrm{t})+\rho \overrightarrow{\mathrm{g}}+\overrightarrow{\mathrm{F}}$

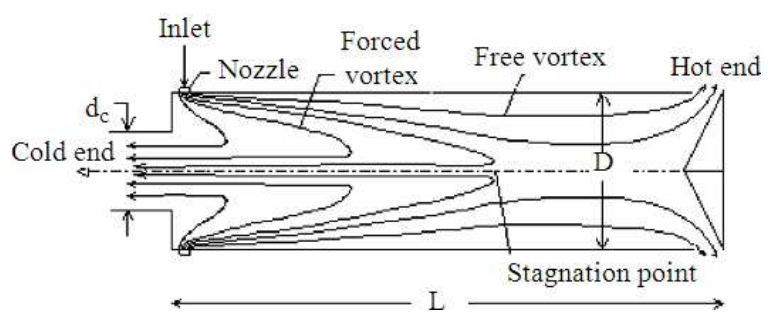

Fig. 1: Schematic flow pattern of Ranque-Hilsch tube

Corresponding Author: K.K. Zin, Department of Energy Conversion Engineering, Technical University of Berlin, Sekr. KT 2, Marchstraße 18, 10587 Berlin, Germany Tel: ++49 (0) 30/314 24614 Fax: ++49 (0) 30/314 22253 
Energy Rec. J. 1 (2): 193-196, 2010

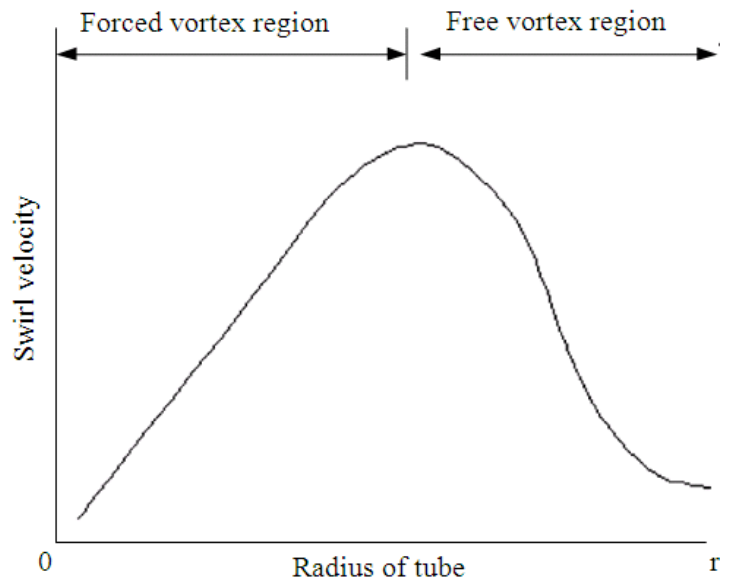

Fig. 2: Schematic velocity distribution of RanqueHilsch tube (Behera et al., 2005)

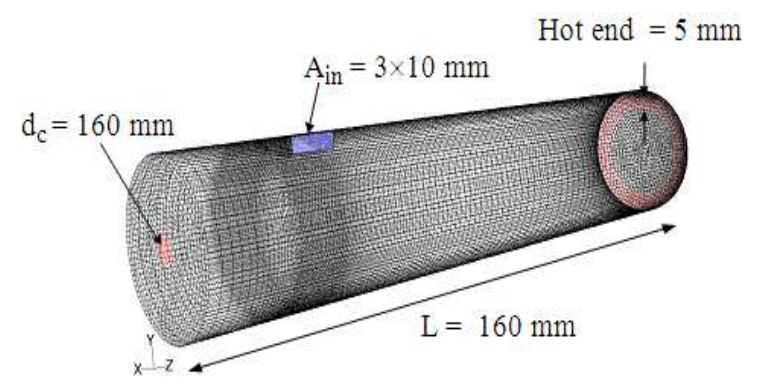

Fig. 3: CFD mesh grid showing of the Ranque-Hilsch tube with $\mathrm{L} / \mathrm{D}$ ratio is 5

The turbulence kinetic energy, $\mathrm{k}$ and its rate of dissipation, $\varepsilon$, are obtained from the following transport equations:

$\frac{\partial}{\partial t}(\rho \mathrm{k})+\frac{\partial}{\partial \mathrm{x}_{\mathrm{i}}}\left(\rho \mathrm{ku}_{\mathrm{i}}\right)=\frac{\partial}{\partial \mathrm{x}_{\mathrm{j}}}\left[\left(\mu+\frac{\mu_{\mathrm{t}}}{\sigma_{\mathrm{k}}}\right) \frac{\partial \mathrm{k}}{\partial \mathrm{x}_{\mathrm{j}}}\right]+\mathrm{G}_{\mathrm{k}}+$

$\mathrm{G}_{\mathrm{b}}-\rho \in-\mathrm{Y}_{\mathrm{M}}+\mathrm{S}_{\mathrm{k}}$

$\frac{\partial}{\partial t}(\rho \in)+\frac{\partial}{\partial x_{i}}\left(\rho \in u_{i}\right)=\frac{\partial}{\partial x_{j}}\left[\left(\mu+\frac{\mu_{t}}{\sigma_{\epsilon}}\right) \frac{\partial \epsilon}{\partial x_{j}}\right]+$

$\mathrm{C}_{1 \varepsilon} \frac{\epsilon}{\mathrm{k}}\left(\mathrm{G}_{\mathrm{k}}+\mathrm{C}_{3 \epsilon} \mathrm{G}_{\mathrm{b}}\right)-\mathrm{C}_{2 \epsilon} \rho \frac{\epsilon^{2}}{\mathrm{k}}+\mathrm{S}_{\epsilon}$

The turbulent (or eddy) viscosity, $\mu_{\mathrm{t}}$, is computed by combining $\mathrm{k}$ and $\varepsilon$ as follows:

$\mu_{\mathrm{t}}=\rho \mathrm{C}_{\mu} \frac{\mathrm{k}^{2}}{\epsilon}$

The model constants $\mathrm{C}_{1 \varepsilon}, \mathrm{C}_{2 \varepsilon}, \mathrm{C}_{\mu}, \sigma_{\mathrm{k}}$ and $\sigma_{\varepsilon}$ have the following default values (FLUENT ${ }^{\mathrm{TM}}$ user guide):

$$
\mathrm{C}_{1 \varepsilon}=1.44, \mathrm{C}_{2 \varepsilon}=1.92, \mathrm{C}_{\mu}=0.09, \sigma_{\mathrm{k}}=1.0, \sigma_{\varepsilon}=1.3
$$

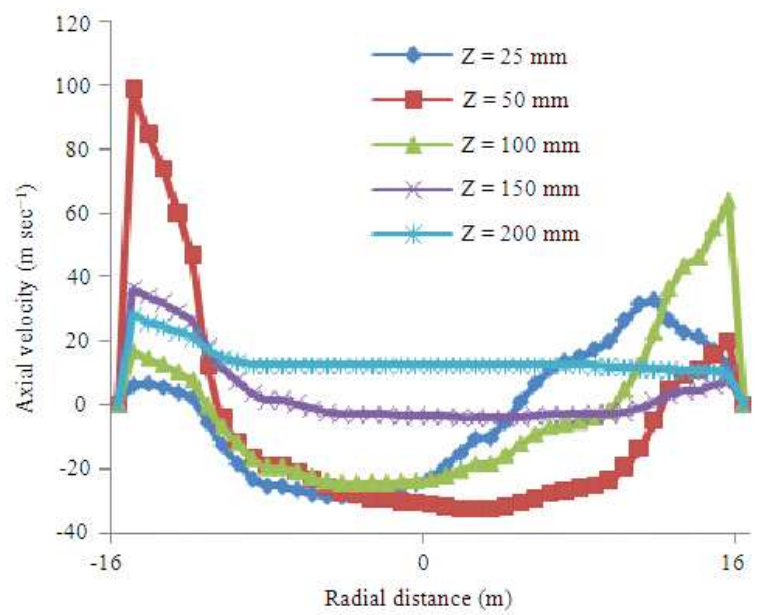

(a)

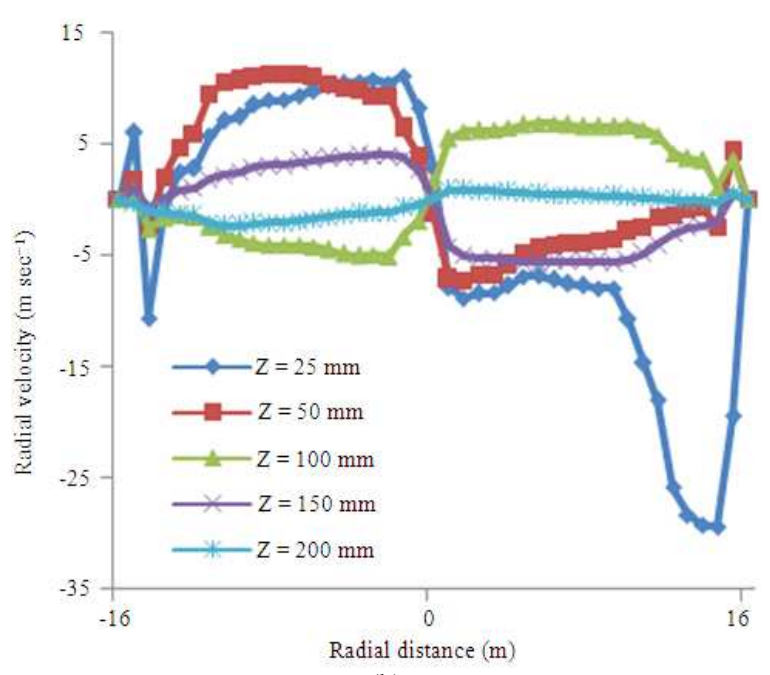

(b)

Fig. 4: Axial and radial velocity components with radial distance (where $\mathrm{Z}$ is the axial distance along the vortex tube)

The working fluid (ideal gas) is the working fluid.

Physical modeling of vortex tube: The geometric model has been carried out with the GAMBIT ${ }^{\mathrm{TM}}$ mesh generation code. A mesh consisting of 170022 grid nodes is shown in Fig. 3. The inlet of $3 \times 10 \mathrm{~mm}$ and the diameter of vortex tube, $\mathrm{D}=32 \mathrm{~mm}$ are kept constant in the analysis. The L/D ratio assumed for the studies ranged from 5-20.

Variations of the velocity components along axial and radial direction are shown in Fig. $4 \mathrm{a}$ and b. The velocity along the axial direction show the evidence of the forced and free vortex zone inside the tube and the existence of secondary flow from the inlet to the cold end and till to the stagnation point. 
Energy Rec. J. 1 (2): 193-196, 2010

Table 1: Fixed and variable parameters for the simulation

\begin{tabular}{llllll}
\hline $\begin{array}{l}\text { Inlet mass flow } \\
\left(\mathrm{kg} \mathrm{sec}^{-1}\right)\end{array}$ & $\begin{array}{l}\text { Inlet pressure } \mathrm{P}_{\text {in }} \\
(\mathrm{kPa})(\text { absolute })\end{array}$ & $\begin{array}{l}\text { Inlet temperature } \\
\mathrm{T}_{\mathrm{in}}(\mathrm{K})(\mathrm{total})\end{array}$ & $\begin{array}{l}\text { Cold exit pressure } \\
\mathrm{Pc}(\mathrm{kPa})(\mathrm{absolute})\end{array}$ & $\begin{array}{l}\text { Cold mass fraction } \\
\mathrm{Y}_{\mathrm{c}}\end{array}$ & $\begin{array}{l}\text { Length and } \\
\text { diameter ratio }\end{array}$ \\
\hdashline 0.015 & 280.000 & 294 & 101.325 & $0.1,0.2,0.35,0.5,0.7$ & $5,10,15,20$ \\
\hline
\end{tabular}

Boundary condition: Boundary conditions for the model were defined based on the experimental measurements. The inlet is modeled as a mass flow inlet; the mass flow rate, total temperature, direction vector and turbulence parameters were specified. The cold and hot outlets are determined as pressure outlets using measured values of the static pressure (Skye et al., 2006).

Study of grid dependence: The fixed and variable parameters for the numerical analysis are listed in Table 1. To eliminate the errors due to coarseness of grid, analysis has been carried out for different average unit cell volumes in a vortex tube of $\mathrm{L} / \mathrm{D}=5$. For a smaller mesh size then reported about the solution is independence from the grid size.

\section{RESULTS}

CFD analyses were carried out for a $32 \mathrm{~mm}$ diameter vortex tube with L/D of 5, 10, 15 and 20 verify the existence of a secondary circulation flow, a stagnation point. And also with the varying amount of cold fraction (i.e., mass flow of cold outlet in relation to the inlet) $0.1,0.2,0.35,0.5,0.7$ has been varied to investigate the variation of static and total pressure as well as the velocity components of the particle as it progresses in the tube, starting from the entry through to the cold and hot exit by tracking the particles to understand the flow phenomenon inside the vortex tube.

The improvement of the CFD result will be achieved by improving the calculation of the pressure loss along the tube.

\section{DISCUSSION}

Velocity components and secondary circulation flow: The velocity magnitude along the center line of the vortex tube with corresponding L/D ratio is shown in Fig. 5. The velocity magnitude comes to zero at an axial distance between 100 and $200 \mathrm{~mm}$ from the cold exit. The stagnation point is almost independent from the tube length which are after the stagnation points there is a vortex the structure is similar to Görtler vortice because of the velocity distribution of the turbulent swirl flow with secondary circulation.

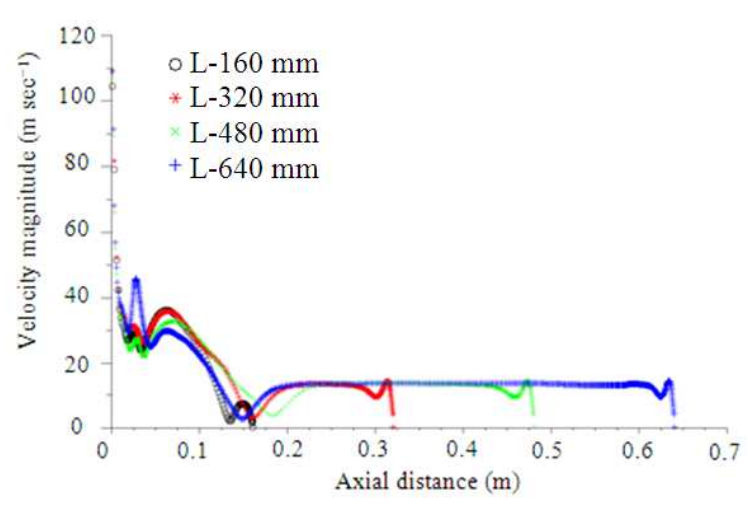

Fig. 5: Velocity magnitude along the center line of the vortex with different L/D ratio

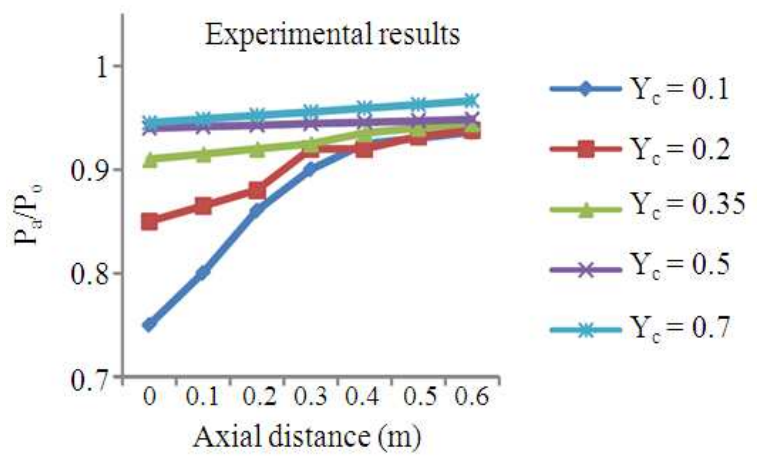

(a)

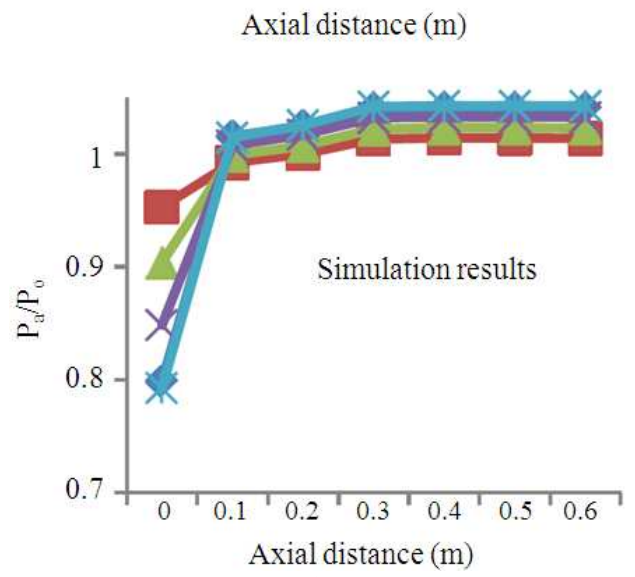

(b)

Fig. 6: Axial absolute pressure gradient along the length of the tube 
Pressure components and experimental verification: A parametric study was carried out to investigate the effect of varying the mass flow rate at the cold and hot exits on the pressure and flow separation. For a simulated and measured L/D ratio of 20 and the cold mass fraction $0.1,0.2$. 0.35, 0.5 and 0.7 , the results are shown in Fig. 6a and b. There is only fair agreement in the total pressures obtained through experiment and by CFD simulation.

\section{CONCLUSION}

A three-dimensional numerical model of the Ranque-Hilsch vortex has been established to analyze the flow inside the tube. The studies have confirmed the presence of a secondary flow. The stagnation point inside the tube is almost independent of the tube length. The velocity profiles in the radial direction at different axial position show that the flow in the vortex tube is largely affected by the forced vortex. However, the disagreement of measured and simulated pressure along the tube length shows that the model still have to be improve.

\section{REFERENCES}

Ahlborn, B.K., J.U. Keller and E. Rebhan, 1998. The heat pump in a vortex tube. J. Non-equilib. Thermodyn., 23: 159-165. http://cat.inist.fr/?aModele $=$ afficheN\&cpsidt $=1053$ 7580

Bruno, T.J., 1992. Applications of the vortex tube in chemical analysis. Process Control Qual., 3: 195-207.
Behera, U., P.J. Paul, S. Kasthurirengan, R. Karunanithi and S.N. Ram et al., 2005. CFD analysis and experimental investigations towards optimizing the parameters of Ranque-Hilsch vortex tube. Int. J. Heat Mass Transfer, 48: 1961-1973. DOI: 10.1016/j.ijheatmasstransfer.2004.12.046

Hansske, A., D. Müller, R. Streblow and F. Ziegler, 2007. Experiments and simulation of a vortex tube. $\quad$ ETA. http://www.eta.tuberlin.de/fileadmin/a33371300/Redakteurbereich/ Forschung/Abstracts/Experiments_and_Simulatio n_of_a_Vortex_Tube_Abstract.pdf

Skye, H.M., G.F. Nellis and S.A. Klein, 2006. Comparison of CFD analysis to empirical data in a commercial vortex tube. Int. J. Refrig., 29: 71-80. DOI: 10.1016/j.ijrefrig.2005.05.004 